MSC 46A16, 47D03, 34D09

DOI: $10.14529 /$ jcem 150403

\title{
ON SOME PROPERTIES OF SOLUTIONS TO DZEKTSER MATHEMATICAL MODEL IN QUASI-SOBOLEV SPACES
}

J.K.T. Al-Isawi, South Ural State University, Chelyabinsk, Russian Federation, jtahir71@gmail.com.

The theory of holomorphic degenerate semigroups of operators constructed earlier in Banach spaces and Frechet spaces is transferred to quasi-Sobolev spaces of sequences. This article contains results about existence of the exponential dichotomies of solutions to evolution Sobolev type equation in quasi-Sobolev spaces. To obtain this result we proved the relatively spectral theorem and the existence of invariant spaces of solutions. All abstract results are applied to investigation of properties of solutions to Dzektser mathematical model in quasi-Sobolev spaces.

The article besides the introduction and references contains three paragraphs. In the first one, quasi-Banach spaces, quasi-Sobolev spaces and polynomials of Laplace quasioperator are defined. Moreover the conditions for existence of degenerate holomorphic operator semigroups in quasi-Banach spaces of sequences are obtained. In other words, we state the first part of generalization of the Solomyak - Iosida theorem to quasi-Sobolev spaces of sequences. In the second paragraph the phase space of the homogeneous equation is constructed. Here we show the existence of invariant spaces of equation and get the conditions for exponential dichotomies of solutions. The last paragraph presents results on properties of solutions to Dzektser equation.

Keywords: Sobolev type equation; holomorphic degenerate semigroup; quasi-Sobolev spaces; invariant space; exponential dichotomy of solution; Dzektser mathematical model.

\section{Introduction}

The article is devoted to a quasi-Banach analogue of homogeneous Dirichlet problem in a bounded domain for linear Dzektser equation [1-4]

$$
(\lambda-\Delta) u_{t}=\beta \Delta u-\alpha \Delta^{2} u+f .
$$

We develop the theory of degenerate semigroups by spreading the results obtained in Banach spaces to quasi-Sobolev spaces.

Firstly holomorphic degenerate semigroups appeared in $[1,5]$ as solving semigroups for evolution Sobolev type equation

$$
L \dot{u}=M u
$$

where operator $L \in \mathcal{L}(\mathfrak{U} ; \mathfrak{F})$, and operator $M \in C l(\mathfrak{U} ; \mathfrak{F}), \mathfrak{U}, \mathfrak{F}$ are Banach spaces. Explicit theory of such semigroups can be found in [6].

Interest in Sobolev type equations has recently increased significantly [7-9], moreover, there arose a necessity for their consideration in quasi-Banach spaces. The need is dictated not so much by the desire to fill up the theory but by the aspiration to comprehend nonclassical models of mathematical physics [2] in quasi-Banach spaces [10]. 
Since the Cauchy problem for the Sobolev type equation is not solvable for arbitrary initial data it is necessary to construct the phase space of equation as the set of admissible initial values containing all solutions of equation [6]. The phase spaces of evolution and dynamical Sobolev type equations were constructed earlier in Banach spaces [6]. Moreover there were found conditions when the phase space splits into direct sum of invariant with respect to equation spaces and the solutions have exponential dichotomies [11]. By now these problems are completely solved in Banach spaces [9]. Our goal is to spread these ideas to one class of evolution Sobolev type equations in quasi-Sobolev spaces of sequences. We construct invariant spaces for the Dzektser equation and obtain conditions when its solutions have exponential dichotomies.

\section{Holomorphic Degenerate Semigroups of Operators}

Let $\mathfrak{U}$ be a lineal over $\mathbb{R}$. An ordered pair $\left(\mathfrak{U}_{\mathfrak{U}}\|\cdot\|\right)$ is called a quasi-normed space, if the function $\mathfrak{U}\|\|:. \mathfrak{U} \rightarrow \mathbb{R}$ satisfies the following conditions:

1. $\mathfrak{U}\|u\| \geq 0$ for all $u \in \mathfrak{U}$, moreover $\mathfrak{U}\|u\|=0$ iff $u=\mathbf{0}$, where $\mathbf{0}$ is a zero element in $\mathfrak{U}$;

2. $\mathfrak{U}\|\alpha u\|=|\alpha|_{\mathfrak{U}}\|u\|$ for all $u \in \mathfrak{U}, \alpha \in \mathbb{R}$;

3. $\mathfrak{U}\|u+v\|=\mathrm{C}(\mathfrak{U}\|u\|+\mathfrak{U}\|v\|)$ for all $u, v \in \mathfrak{U}$, where the constant $C \geq 1$.

The function $\mathfrak{u}\|u\|$ with properties (i)-(iii) is called a quasi-norm. Obviously, in case $C=1$ this function is a norm.

The metrizable complete quasi-normed space is called a quasi-Banach space. The spaces of sequences $\ell_{q}, q \in(0,1)$ are well known quasi-Banach spaces (for $q \in[1,+\infty$ ) the spaces $\ell_{q}$ are Banach spaces).

Let henceforth $\left\{\lambda_{k}\right\} \subset \mathbb{R}_{+}$be a monotone sequence such that $\lim _{k \rightarrow \infty} \lambda_{k}=+\infty$. The quasi-Banach space

$$
\ell_{q}^{m}=\left\{u=\left\{u_{k}\right\}: \sum_{k=1}^{\infty}\left(\lambda_{k}^{\frac{m}{2}}\left|u_{k}\right|\right)^{q}<+\infty\right\}
$$

with a quasi-norm ${ }_{q}^{m}\|u\|=\left(\sum_{k=1}^{\infty}\left(\lambda_{k}^{\frac{m}{2}}\left|u_{k}\right|\right)^{q}\right)^{1 / q}, m \in \mathbb{R}$ is called a quasi-Sobolev space.

Obviously, for $q \in[1,+\infty)$ the spaces $\ell_{q}^{m}$ are Banach spaces; $\ell_{q}^{0}=\ell_{q}$, and there is a dense and continuous embedding $\ell_{q}^{n}$ into $\ell_{q}^{m}$ for $n>m$ and $q \in \mathbb{R}_{+}$.

Example 1. Let $\mathfrak{U}=\ell_{q}^{m+2 n}, \mathfrak{F}=\ell_{q}^{m} ; Q_{n}(\lambda)$ be a polynomial of power $n$. Consider operator $Q_{n}(\Lambda) u=\left\{Q_{n}\left(\lambda_{k}\right) u_{k}\right\}, n \in \mathbb{N}$, where $\left\{u_{k}\right\} \in \mathfrak{U}$. It is easy to see that operator $Q_{n}(\Lambda) \in \mathcal{L}(\mathfrak{U} ; \mathfrak{F})$, moreover $Q_{n}(\Lambda): \ell_{q}^{m+2 n} \rightarrow \ell_{q}^{m}$ is a toplinear isomorphism.

Let $\mathfrak{U}$ and $\mathfrak{F}$ be quasi-Banach spaces, operators $L \in \mathcal{L}(\mathfrak{U} ; \mathfrak{F})$ and $M \in C l(\mathfrak{U} ; \mathfrak{F})$, following [5, 6], take into consideration L-resolvent set $\rho^{L}(M)=\left\{\mu \in \mathbb{C}:(\mu L-M)^{-1} \in\right.$ $\mathcal{L}(\mathfrak{F} ; \mathfrak{U})\}$ and $L$-spectrum $\sigma^{L}(M)=\mathbb{C} \backslash \rho^{L}(M)$ of operator $M$. It is easy to show that the set $\rho^{L}(M)$ is always opened, therefore the $L$-spectrum of operator $M$ is always closed.

Definition 1. Operator $M$ is called strongly $(L, p)$-sectorial, $p \in\{0\} \cup \mathbb{N}$, if

(i) there exist constants $a \in \mathbb{R}$ and $\theta \in(\pi / 2 ; \pi)$ such that the sector 


$$
S_{a, \theta}^{L}(M)=\{\mu \in \mathbb{C}:|\arg (\mu-a)|<\theta, \mu>a\} \subset \rho^{L}(M) ;
$$

(ii) there exists a constant $K \in \mathbb{R}_{+}$such that

$$
\max \left\{\mathcal{L}(\mathfrak{U})\left\|R_{(\mu, p)}^{L}(M)\right\|, \mathcal{L}(\mathfrak{F})\left\|L_{(\mu, p)}^{L}(M)\right\|\right\} \leq \frac{K}{\prod_{k=0}^{p}\left|\mu_{k}-a\right|},
$$

for all $\mu_{0}, \mu_{1}, \ldots, \mu_{p} \in S_{a, \theta}^{L}(M)$. Here $R_{(\mu, p)}^{L}(M)=\prod_{k=0}^{p} R_{\mu_{k}}^{L}(M)$ is the right and $L_{(\mu, p)}^{L}(M)=\prod_{k=0}^{p} L_{\mu_{k}}^{L}(M)$ is the left $(L, p)$-resolvent of operator $M$, and $R_{\mu}^{L}(M)=(\mu L-M)^{-1} L$ and $L_{\mu}^{L}(M)=L(\mu L-M)^{-1}$ are the right and the left $L$-resolvents of operator $M$ respectively.

(iii) there exists a dense in $\mathfrak{F}$ lineal $\mathfrak{F}^{0}$ such that

$$
\mathfrak{F}\left\|M(\lambda L-M)^{-1} L_{(\mu, p)}^{L}(M) f\right\| \leq \frac{\text { const }}{|\lambda| \prod_{k=0}^{p}\left|\mu_{k}\right|} \text { for all } f \in \mathfrak{F}^{0}
$$

where const $=\operatorname{const}(f)$; for all $\lambda, \mu_{k} \in S_{\theta}^{L}(M), k=0, \ldots, p$.

(iv)

$$
\mathcal{L}(\mathfrak{F} ; \mathfrak{L})\left\|(\lambda L-M)^{-1} L_{(\mu, p)}^{L}(M)\right\| \leq \frac{\text { const }}{|\lambda| \prod_{k=0}^{p}\left|\mu_{k}\right|}
$$

for arbitrary $\lambda, \mu_{k} \in S_{\theta}^{L}(M), k=0, \ldots, p$ and some const $\in \mathbb{R}_{+}$.

Example 2. Let $\mathfrak{U}=\ell_{q}^{m+2 n}, \mathfrak{F}=\ell_{q}^{m}, m \in \mathbb{R}, q \in \mathbb{R}_{+}, Q_{n}(\lambda)=\sum_{i=0}^{n} c_{i} \lambda^{i} R_{s}(\lambda)=\sum_{j=0}^{s} d_{j} \lambda^{j}$ be polynomials of powers $n$ and $s$ respectively $(n<s)$ with real coefficients $\left(\frac{d_{s}}{c_{n}}<0\right)$, without common roots. Construct operators $L=Q_{n}(\Lambda), M=R_{s}(\Lambda)$ as in example 1 . It is easy to show that $R_{s}(\Lambda) \in \mathcal{C l}(\mathfrak{U} ; \mathfrak{F}), \operatorname{dom} R_{s}(\Lambda)=\ell_{q}^{m+2 s}$, the $L$-spectrum $\sigma^{L}(M)$ of operator $M$ consists of points $\mu_{k}=R_{s}\left(\lambda_{k}\right)\left(Q_{n}\left(\lambda_{k}\right)\right)^{-1}, k \in \mathbb{N}: \lambda_{k}$ is not the root of the polynomial $Q_{n}(\lambda)$.

Lemma 1. [12] Operator $M$ defined in example 2 is strongly (L,0)-sectorial.

Theorem 1. [12] Let operators $M$ and $L$ be defined as in example 2. Then

(i) operators $L$ and $M$ generate holomorphic semigroups $\left\{U^{t}: t \in \mathbb{R}_{+}\right\}$and $\left\{F^{t}: t \in\right.$ $\left.\mathbb{R}_{+}\right\}$on spaces $\mathfrak{U}$ and $\mathfrak{F}$ respectively given by

$$
U^{t}=\frac{1}{2 \pi i} \int_{\Gamma} R_{\mu}^{L}(M) e^{\mu t} d \mu \in \mathcal{L}(\mathfrak{U}) \quad F^{t}=\frac{1}{2 \pi i} \int_{\Gamma} L_{\mu}^{L}(M) e^{\mu t} d \mu \in \mathcal{L}(\mathfrak{F})
$$

for $t \in \mathbb{R}_{+}$, where the contour $\Gamma \subset \rho^{L}(M)$ is such that $|\arg \mu| \rightarrow \theta$ npu $\mu \rightarrow \infty, \mu \in \Gamma$.

(ii) there exist semigroup's units which are the projectors $P \in \mathcal{L}(\mathfrak{U})$ and $Q \in \mathcal{L}(\mathfrak{F})$ given by

$$
P= \begin{cases}\mathbb{I}, & \text { if } \lambda_{k} \text { is not the root of } Q_{n}(\lambda) \text { for all } k \in \mathbb{N} \\ \mathbb{I}-\sum_{k \in \mathbb{N}: k=\ell}<., e_{k}>e_{k}, & \text { if there exist } \ell \in \mathbb{N}: \lambda_{\ell} \text { is the root of } Q_{n}(\lambda),\end{cases}
$$

(the projector $Q$ has the same form), splitting the quasi-Banach spaces $\mathfrak{U}$ and $\mathfrak{F}$ into direct sums

$$
\mathfrak{U}=\mathfrak{U}^{0} \oplus \mathfrak{U}^{1}, \quad \mathfrak{F}=\mathfrak{F}^{0} \oplus \mathfrak{F}^{1}
$$


(iii) there is splitting of operator actions $L_{k} \in \mathcal{L}\left(\mathfrak{U}^{k} ; \mathfrak{F}^{k}\right), M_{k} \in C l\left(\mathfrak{U}^{k} ; \mathfrak{F}^{k}\right), k=0,1$, and existence of operators $M_{0}^{-1} \in \mathcal{L}\left(\mathfrak{F}^{0} ; \mathfrak{U}^{0}\right), L_{1}^{-1} \in \mathcal{L}\left(\mathfrak{F}^{1} ; \mathfrak{U}^{1}\right)$;

(iv) operators $H=M_{0}^{-1} L_{0}\left(G=L_{0} M_{0}^{-1}\right)$ are nilpotent and operators $S=L_{1}^{-1} M_{1}$ : $\operatorname{dom} M \cap$ $\mathfrak{U}^{1} \rightarrow \mathfrak{U}^{1}$ and $T=M_{1} L_{1}^{-1}: M[\operatorname{dom} M] \cap \mathfrak{F}^{1} \rightarrow \mathfrak{F}^{1}$ are sectorial.

\section{Invariant Spaces and Exponential Dichotomies of Solutions}

Let $\mathfrak{U}$ and $\mathfrak{F}$ be quasi-Sobolev spaces of sequences, operators $L \in \mathcal{L}(\mathfrak{U} ; \mathfrak{F})$ and $M \in$ $\mathrm{Cl}(\mathfrak{U} ; \mathfrak{F})$ be constructed in example 2. Consider linear evolution Sobolev type equation

$$
L \dot{u}=M u \text {. }
$$

Vector-function $u \in C^{1}\left(\mathbb{R}_{+} ; \mathfrak{U}\right)$, satisfying (3) pointwise is called (a classical solution of this equation. The solution $u=u(t)$ of $(3)$ is called a solution to the weakened Cauchy problem (in sense of S.G. Krein), if in addition for $u_{0} \in \mathfrak{U}$

$$
\lim _{t \rightarrow 0+} u(t)=u_{0}
$$

holds.

Definition 2. The set $\mathfrak{P} \subset \mathfrak{U}$ is called a phase space of equation (3), if

(i) any solution $u=u(t)$ of (3) lies in $\mathfrak{P}$ pointwise, i.e. $u(t) \in \mathfrak{P}$ for all $t \in \mathbb{R}_{+}$;

(ii) for all $u_{0} \in \mathfrak{P}$ there exists a unique solution to (3), (4).

Theorem 2. [12] Let operators $M$ and $L$ be defined as in example (2). Then the subspace $\mathfrak{U}^{1}$ is a phase space of (3).

Consider the following condition:

Let $\sigma^{L}(M)=\sigma_{1}^{L}(M) \cup \sigma_{2}^{L}(M)$ and $\sigma_{1}^{L}(M)$ is not empty, there exists a bounded domain $\Omega_{1} \subset \mathbb{C}$ with a boundary of class $C^{1}$, such that $\Omega_{1} \supset \sigma_{1}^{L}(M)$ and $\bar{\Omega}_{1} \bigcap \sigma_{2}^{L}(M)$ is empty.

If this condition holds then there exist [11] operators given by integrals

$$
P_{1}=\frac{1}{2 \pi i} \int_{\gamma_{1}} R_{\mu}^{L}(M) d \mu \text { and } Q_{1}=\frac{1}{2 \pi i} \int_{\gamma_{1}} L_{\mu}^{L}(M) d \mu,
$$

where $\gamma_{1}=\partial \Omega_{1}$. By construction operators $P_{1} \in \mathcal{L}(\mathfrak{U})$ and $Q_{1} \in \mathcal{L}(\mathfrak{F})$.

Lemma 2. Let $L, M \in \mathcal{L}(\mathfrak{U} ; \mathfrak{F})$ be defined in example 2 and condition (5) hold then operators $P_{1} \in \mathcal{L}(\mathfrak{U})$ and $Q_{1} \in \mathcal{L}(\mathfrak{F})$ are projectors in corresponding spaces.

Put $\mathfrak{U}^{11}=\operatorname{im} P_{1}, \mathfrak{F}^{11}=\operatorname{im} Q_{1}, \mathfrak{U}^{10}=\operatorname{ker} P_{1}, \mathfrak{F}^{10}=\operatorname{ker} Q_{1}$; and by $L_{11}\left(M_{11}\right)$ denote restriction of operator $L(M)$ onto $\mathfrak{U}^{11}$.

Theorem 3. [13] Let conditions of lemma 2 be fulfilled. Then

(i) operators $L_{11}, M_{11} \in \mathcal{L}\left(\mathfrak{U}^{11} ; \mathfrak{F}^{11}\right)$;

(ii) there exists an operator $L_{11}^{-1} \in \mathcal{L}\left(\mathfrak{F}^{11} ; \mathfrak{U}^{11}\right)$.

Corollary 1. [13] Let conditions of lemma 2 be fulfilled. Then $P_{1}=P P_{1}=P_{1} P$ and $Q_{1}=Q Q_{1}=Q_{1} Q$. 
Construct operators $P_{2}=P-P_{1}$ and $Q_{2}=Q-Q_{1}$. Due to corollary 1 these operators are projectors. Put $\mathfrak{U}^{12}=\operatorname{im} P_{2}, \mathfrak{F}^{12}=\operatorname{im} Q_{2}$ and by $L_{12}\left(M_{12}\right)$ denote restriction of operator $L(M)$ onto $\mathfrak{U}^{12}$.

Corollary 2. [13] Let conditions of lemma 2 be fulfilled. Then

(i) $\mathfrak{U}=\mathfrak{U}^{0} \oplus \mathfrak{U}^{1}, \quad \mathfrak{F}=\mathfrak{F}^{0} \oplus \mathfrak{F}^{1}, \quad \mathfrak{U}^{1}=\mathfrak{U}^{11} \oplus \mathfrak{U}^{12}, \quad \mathfrak{F}^{1}=\mathfrak{F}^{11} \oplus \mathfrak{F}^{12} ;$

(ii) operators $L_{12}, M_{12} \in \mathcal{L}\left(\mathfrak{U}^{12} ; \mathfrak{F}^{12}\right)$;

(iii) there exists an operator $L_{12}^{-1} \in \mathcal{L}\left(\mathfrak{F}^{12} ; \mathfrak{U}^{12}\right)$.

Definition 3. Let $\mathfrak{P}$ be a phase space of (3). The subset $\mathfrak{J} \subset \mathfrak{P}$ is called an invariant space of equation (3), if for arbitrary $u_{0} \in \mathfrak{J}$ the solution $u=u(t)$ of $(3)$, (4) lies in $\mathfrak{J}$ pointwise (i.e. $u(t) \in \mathfrak{J}$ for all $t \in R_{+}$).

Theorem 4. [13] Let operators $L, M \in \mathcal{L}(\mathfrak{U} ; \mathfrak{F})$ be defined as in example 2 and condition (5) hold then the image of group

$$
V^{t}=\frac{1}{2 \pi i} \int_{\gamma_{1}} R_{\mu}^{L}(M) e^{\mu t} d \mu, t \in R,
$$

is an invariant space of (3).

Definition 4. We say that solutions of (3) have exponential dichotomy, if

(i) the phase space of (3) can be represented as $\mathfrak{P}=\mathfrak{J}^{1} \oplus \mathfrak{J}^{2}$, where $\mathfrak{J}^{1(2)}$ are invariant spaces of equation (3);

(ii) for arbitrary $u_{0} \in \mathfrak{J}^{1}\left(u_{0} \in \mathfrak{J}^{2}\right)$ solution $u=u(t)$ of (3), (4) is such that $\mathfrak{U}\|u(t)\| \leq$ $C_{1} e^{-a t} \mathfrak{U}\left\|u_{0}\right\|\left(\mathfrak{U}\|u(t)\| \geq C_{2} e^{a t} \mathfrak{u}\left\|u_{0}\right\|\right)$ for some $a>0$ and all $t \in R_{+}$.

Theorem 5. [13] Let operators $L, M \in \mathcal{L}(\mathfrak{U} ; \mathfrak{F})$ be defined as in example 2 and condition

$$
\sigma^{L}(M) \cap i \mathbb{R}=\emptyset
$$

hold. Then solutions of (3) have exponential dichotomy.

\section{Properties of Solutions to Dzektser Mathematical Model}

Consider Dzektser equation

$$
(\lambda-\Lambda) u_{t}=\left(\alpha \Lambda^{2}+\beta \Lambda\right) u+f, \lambda, \beta \in \mathbb{R}, \quad \alpha \in \mathbb{R}_{+}
$$

in quasi-Sobolev spaces $\mathfrak{U}=\ell_{q}^{m+2}$ and $\mathfrak{F}=\ell_{q}^{m}, m \in \mathbb{R}, q \in \mathbb{R}_{+}$. Define the domain $\operatorname{dom}\left(\alpha \Lambda^{2}+\beta \Lambda\right)=\ell_{q}^{m+4}$.

By theorem 1 we have the following

Corollary 3. For all $m, \lambda, \beta \in \mathbb{R} \tau, q, \alpha \in \mathbb{R}_{+}, u_{0} \in \mathfrak{U}, f^{0} \in C^{1}\left((0, \tau) ; \mathfrak{F}^{0}\right)$ and $f^{1} \in$ $C\left((0, \tau) ; \mathfrak{F}^{1}\right)$ there exists a unique solution $u \in C^{1}((0, \tau) ; \mathfrak{U})$ of $(4),(7)$, given by

$$
u(t)=-M_{0}^{-1} f^{0}(t)+U^{t} u_{0}+\int_{0}^{t} U^{t-s} L_{1}^{-1} f^{1}(s) d s .
$$

Here

$$
\mathfrak{F}^{0}=\left\{\begin{array}{l}
\{0\}, \text { if } \lambda_{k} \neq \lambda \text { for all } k \in \mathbb{N} ; \\
\left\{f \in \mathfrak{F}: f_{k}=0, \quad k \in \mathbb{N} \backslash\left\{\ell: \lambda_{\ell}=\lambda\right\}\right\}
\end{array}\right.
$$




$$
\begin{gathered}
\mathfrak{F}^{1}=\left\{\begin{array}{l}
\mathfrak{F}, \text { if } \lambda_{k} \neq \lambda \text { for all } k \in \mathbb{N} ; \\
\left\{f \in \mathfrak{F}: f_{k}=0, \lambda_{k}=\lambda\right\} ;
\end{array}\right. \\
M_{0}^{-1}= \begin{cases}\mathbb{O}, & \text { if } \lambda_{k} \neq \lambda \text { for all } k \in \mathbb{N} ; \\
\sum_{k \in \mathbb{N}: \lambda_{k}=\lambda}\left(\alpha \lambda_{k}^{2}+\beta \lambda_{k}\right)^{-1}<., e_{k}>e_{k} .\end{cases} \\
U^{t}= \begin{cases}\sum_{k=1}^{\infty} e^{\mu_{k} t}<., e_{k}>e_{k}, & \text { if } \lambda_{k} \neq \lambda \text { for all } k \in \mathbb{N} ; \\
\sum_{k \in \mathbb{N}: k \neq \ell} e^{\mu_{k} t}<., e_{k}>e_{k}, & \text { if there exist } \ell \in \mathbb{N}: \lambda_{\ell}=\lambda,\end{cases}
\end{gathered}
$$

where $\mu_{k}=\left(\alpha \lambda_{k}^{2}+\beta \lambda_{k}\right)\left(\lambda-\lambda_{k}\right)^{-1}$.

$$
L_{1}^{-1}= \begin{cases}\sum_{k=1}^{\infty}\left(\lambda-\lambda_{k}\right)^{-1}<., e_{k}>e_{k}, & \text { if } \lambda_{k} \neq \lambda \text { for all } k \in \mathbb{N} \\ \sum_{k \in \mathbb{N}: k \neq \ell}\left(\lambda-\lambda_{k}\right)^{-1}<., e_{k}>e_{k}, & \text { if there exist } \ell \in \mathbb{N}: \lambda_{\ell}=\lambda .\end{cases}
$$

Let's investigate the properties of solutions to homogenious equation (7). Consider the following condition:

Let $\sigma^{L}(M)=\sigma_{1}^{L}(M) \cup \sigma_{2}^{L}(M)$;

$\sigma_{1}^{L}(M)$ consists of finite number of points $\left\{\mu_{k}\right\} \subset \sigma^{L}(M)$;

$\Omega_{1} \subset \mathbb{C}$ is a disc containing the points of $\sigma_{1}^{L}(M)$ and $\bar{\Omega}_{1} \cap \sigma_{2}^{L}(M)=\emptyset$.

Obviously, due to (8) condition (5) holds. Then by lemma 2 there exist projectors

$$
P_{1}=\sum_{\mu_{k} \in \sigma_{1}^{L}(M)}<., e_{k}>e_{k} \text { and } Q_{1}=\sum_{\mu_{k} \in \sigma_{1}^{L}(M)}<., e_{k}>e_{k} .
$$

Construct the spaces

$$
\begin{aligned}
& \mathfrak{U}^{11}=\operatorname{im} P_{1}=\left\{u \in \mathfrak{U}: u_{k}=0 \text { if } \mu_{k} \notin \sigma_{1}^{L}(M)\right\}, \\
& \mathfrak{F}^{11}=\operatorname{im} Q_{1}=\left\{f \in \mathfrak{F}: f_{k}=0 \text { if } \mu_{k} \notin \sigma_{1}^{L}(M)\right\}, \\
& \mathfrak{U}^{10}=\operatorname{ker} P_{1}=\left\{u \in \mathfrak{U}: u_{k}=0 \text { if } \mu_{k} \in \sigma_{1}^{L}(M)\right\}, \\
& \mathfrak{F}^{10}=\operatorname{ker} Q_{1}=\left\{f \in \mathfrak{F}: f_{k}=0 \text { if } \mu_{k} \in \sigma_{1}^{L}(M)\right\},
\end{aligned}
$$

and by

$$
\begin{gathered}
L_{11}=\sum_{\mu_{k} \in \sigma_{1}^{L}(M)}\left(\lambda-\lambda_{k}\right)<., e_{k}>e_{k} \\
\left(M_{11}=\sum_{\mu_{k} \in \sigma_{1}^{L}(M)}\left(\alpha \lambda_{k}^{2}+\beta \lambda_{k}\right)<., e_{k}>e_{k}\right)
\end{gathered}
$$

denote restriction of operator $L(M)$ onto $\mathfrak{U}^{11}$.

Construct operators

$$
P_{2}=P-P_{1}=\sum_{\mu_{k} \in \sigma^{L}(M) \backslash \sigma_{1}^{L}(M)}<., e_{k}>e_{k} \text { and } Q_{2}=Q-Q_{1}=\sum_{\mu_{k} \in \sigma^{L}(M) \backslash \sigma_{1}^{L}(M)}<., e_{k}>e_{k} .
$$


Due to corollary 1 these operators are projectors. Put

$$
\begin{aligned}
& \mathfrak{U}^{12}=\operatorname{im} P_{2}=\left\{u \in \mathfrak{U}^{1}: u_{k}=0 \text { if } \mu_{k} \in \sigma_{1}^{L}(M)\right\} \\
& \mathfrak{F}^{12}=\operatorname{im} Q_{2}=\left\{f \in \mathfrak{F}^{1}: f_{k}=0 \text { if } \mu_{k} \in \sigma_{1}^{L}(M)\right\}
\end{aligned}
$$

and by

$$
\begin{aligned}
L_{12} & =\sum_{\mu_{k} \in \sigma^{L}(M) \backslash \sigma_{1}^{L}(M)}\left(\lambda-\lambda_{k}\right)<., e_{k}>e_{k} \\
\left(M_{12}\right. & \left.=\sum_{\mu_{k} \in \sigma^{L}(M) \backslash \sigma_{1}^{L}(M)}\left(\alpha \lambda_{k}^{2}+\beta \lambda_{k}\right)<., e_{k}>e_{k}\right)
\end{aligned}
$$

denote restriction of operator $L(M)$ onto $\mathfrak{U}^{12}$.

Corollary 4.

(i) $\mathfrak{U}=\mathfrak{U}^{0} \oplus \mathfrak{U}^{1}, \quad \mathfrak{F}=\mathfrak{F}^{0} \oplus \mathfrak{F}^{1}, \quad \mathfrak{U}^{1}=\mathfrak{U}^{11} \oplus \mathfrak{U}^{12}, \quad \mathfrak{F}^{1}=\mathfrak{F}^{11} \oplus \mathfrak{F}^{12}$;

(ii) operators $L_{12}, M_{12} \in \mathcal{L}\left(\mathfrak{U}^{12} ; \mathfrak{F}^{12}\right)$;

(iii) there exists an operator $L_{12}^{-1} \in \mathcal{L}\left(\mathfrak{F}^{12} ; \mathfrak{U}^{12}\right)$.

Proof. (i) and (ii) are obvious. Operator

$$
L_{12}^{-1}=\sum_{\mu_{k} \in \sigma^{L}(M) \backslash \sigma_{1}^{L}(M)}\left(\lambda-\lambda_{k}\right)^{-1}<., e_{k}>e_{k} .
$$

Theorem 6. The space $\mathfrak{U}^{11}$ which is the image of group

$$
V^{t}=\frac{1}{2 \pi i} \int_{\gamma_{1}} R_{\mu}^{L}(M) e^{\mu t} d \mu, t \in \mathbb{R}
$$

and the space $\mathfrak{U}^{12}$ are invariant spaces of (7).

Theorem 7. If Re $\mu_{k} \neq 0$ for all $\mu_{k} \in \sigma^{L}(M)$ then solutions of (7) have exponential dichotomy.

The author would like to thank Alyona Zamyshlyaeva for the support and given opportunities.

\section{References}

1. Sviridyuk G.A. On the General Theory of Operator Semigroups. Russian Mathematical Surveys, 1994, vol. 49, no. 4, pp. 45-74. DOI: 10.1070/RM1994v049n04ABEH002390

2. Sviridyuk G.A., Zagrebina S.A. Nonclassical Models of Mathematical Physics. Bulletin of the South Ural State University. Series: Mathematical Modelling, Programming and Computer Software, 2012, no. 40 (299), issue 14, pp. 7-18. (in Russian)

3. Sviridyuk G.A. Solutions Manifolds of One Class of Evolution and Dynamical Equations. Doklady Academii Nauk, 1989, vol. 304, no. 2, pp. 301-304. (in Russian)

4. Sviridyuk G.A., Sukhanova M.V. Solvability of the Cauchy Problem for Linear Singular Evolution Type Equations. Differential Equations, 1992, vol. 28, no. 3, pp. 323-330. (in Russian) 
5. Sviridyuk G.A. Phase Spaces of Semilinear Sobolev Type Equations with Relatively Strongly Sectorial Operator. St. Petersburg Mathematical Journal, 1994, vol. 6, no. 5, pp. 1109-1126.

6. Sviridyuk G.A., Fedorov V.E. Linear Sobolev Type Equations and Degenerate Semigroups of Operators. Utrecht, Boston, VSP, 2003. DOI: 10.1515/9783110915501

7. Zamyshlyaeva A.A. Linear Sobolev Type Equations of High Order. Chelyabinsk, Publishing center of SUSU, 2012. (in Russian)

8. Manakova N.A. Problems of Optimal Control for the Semilinear Sobolev Type Equations. Chelyabinsk, Publishing center of SUSU, 2012. (in Russian)

9. Sagadeeva M.A. Dihotomies of Solutions to Linear Sobolev Type Equations. Chelyabinsk, Publishing center of SUSU, 2012. (in Russian)

10. Al-Delfi J.K. Quasi-Sobolev Spaces $\ell_{p}^{m}$. Bulletin of the South Ural State University. Series: Mathematics. Mechanics. Physics, 2013, vol. 5, no. 1, pp. 107-109. (in Russian)

11. Sviridyuk G.A., Keller A.V. Invariant Spaces and Dichotomies of Solutions of a Class of Linear Equations of Sobolev Type. Russian Mathematics, 1997, vol. 41, no. 5, pp. 57-65.

12. Zamyshlyaeva A.A., Al-Isawi J.K.T. Holomorphic Degenerate Operator Semigroups and Evolution Sobolev Type Equations in Quasi-Banach Spaces of Sequences. Bulletin of the South Ural State University. Series: Mathematics. Mechanics. Physics, 2015, vol. 7, no. 4, pp. 27-36. DOI: 10.14529/mmph150404 (in Russian)

13. Zamyshlyaeva A.A., Al-Isawi J.K.T. On Some Properties of Solutions to One Class of Evolution Sobolev Type Mathematical Models in Quasi-Sobolev Spaces. Bulletin of the South Ural State University. Series: Mathematical Modelling, Programming and Computer Software, 2015, vol. 8, no. 4, pp. 113-119. DOI: 10.14529/mmp150410

Jawad Kadim Tahir Al-Isawi, postgraduate student, department of Equations of Mathematical Physics, South Ural State University, Chelyabinsk, Russian Federation, jtahir71@gmail.com.

Received November 7, 2015

УДК 517.9

DOI: $10.14529 /$ jcem150403

\title{
О НЕКОТОРЫХ СВОЙСТВАХ РЕШЕНИЙ МАТЕМАТИЧЕСКОЙ МОДЕЛИ ДЗЕКЦЕРА В КВАЗИСОБОЛЕВЫХ ПРОСТРАНСТВАХ
}

\author{
Дәж.К.Т. Аль Исави
}

Теория голоморфных вырожденных полугрупп операторов, построенная ранее в банаховых пространствах и пространствах Фреше, распространяется на квазисоболевы пространства последовательностей. Статья содержит результаты о существовании 
экспоненциальных дихотомий решений эволюционного уравнения соболевского типа в квазисоболевых пространствах. Для получения этого результата доказаны относительно спектральная теорема и существование инвариантных пространств уравнения. Все абстрактные результаты применяются в исследовании свойств решений математической модели Дзекцера в квазисоболевых пространствах.

Статья кроме введения и списка литературы, содержит три параграфа. В первом определяются квазибанаховы (квазисоболевы) пространства и многочлены от квазиоператора Лапласа. Более того, приводятся условия существования вырожденных голоморфных полугрупп операторов в квазибанаховых пространствах последовательностей. Другими словами, доказывается первая часть обобщения теоремы Соломяка - Иосиды на квазибанаховы пространства последовательностей. Во втором параграфе строится фазовое пространство однородного уравнения, а также показывается существование инвариантных пространств уравнения. Кроме того, получены условия существования экспоненциальных дихотомий решений. В последнем параграфе представлены результаты о свойствах решений уравнения Дзекцера в квазисоболевых пространствах

Ключевые слова: уравнение соболевского типа; голоморфные вырожденные полугруппы; квазисоболевы пространства; инвариантное пространство; экспоненциальные дихотомии решений; математическая модель Дзекиера.

\section{Литература}

1. Свиридюк, Г.А. К общей теории полугрупп операторов / Г.А. Свиридюк // Успехи математических наук. - 1994. - Т. 49, № 4. - С. 47-74.

2. Свиридюк, Г.А. Неклассические модели математической физики / Г.А. Свиридюк, С.А. Загребина // Вестник ЮУрГУ. Серия: Математическое моделирование и программирование. - 2012. - № 40 (299). - С. 7-18.

3. Свиридюк, Г.А. Многообразия решений одного класса эволюционных и динамических уравнений / Г.А. Свиридюк // Доклады Академии наук. - 1989. - Т. 304, № 2. - С. 301-304.

4. Свиридюк, Г.А. Разрешимость задачи Коши для линейных сингулярных уравнений эволюционного типа / Г.А. Свиридюк, М.В. Суханова // Дифференциальные уравнения. - 1992. - Т. 28, № 3. - С. 323-330.

5. Свиридюк, Г.А. Фазовые пространства полулинейных уравнений типа Соболева с относительно сильно секториальным оператором / Г.А. Свиридюк // Алгебра и анализ. - 1994. - Т. 6, № 5. - С. 252-272.

6. Sviridyuk, G.A. Linear Sobolev Type Equations and Degenerate Semigroups of Operators / G.A. Sviridyuk, V.E. Fedorov. - Utrecht, Boston: VSP, 2003.

7. Замышляева, А.А. Линейные уравнения соболевского типа выского порядка А.А. Замышляева. - Челябинск: Издат. центр ЮУрГУ, 2012.

8. Манакова, Н.А. Задачи оптимального управления для полулинейных уравнений соболевского типа / Н.А. Манакова. - Челябинск: Издат. центр ЮУрГУ, 2012.

9. Сагадеева, М.А. Дихотомии решений линейных уравнений соболевского типа / М.А. Сагадеева. - Челябинск: Издат. центр ЮУрГУ, 2012.

10. Аль-Делфи, Дж.К. Квазисоболевы пространства $\ell_{\mathrm{p}}^{\mathrm{m}} /$ Дж.К. Аль-Делфи // Вестник ЮУрГУ. Серия: Математика. Механика. Физика. - 2013. - Т. 5, № 1. C. $107-109$. 
11. Свиридюк, Г.А. Инвариантные пространства и дихотомии решений одного класса линейных уравнений типа Соболева / Г.А. Свиридюк, А.В. Келлер // Известия вузов. Математика. - 1997. - № 5. - С. 60-68.

12. Замышляева, А.А. Голоморфные вырожденные полугруппы операторов и эволюционные уравнения соболевского типа в квазисоболевых пространствах последовательностей / А.А. Замышляева, Дж.К. Аль-Исави // Вестник ЮУрГУ. Серия: Математика. Механика. Физика. - 2015. - Т. 7, № 4. - С. 31-40.

13. Замышляева, А.А. Голоморфные вырожденные полугруппы операторов и эволюционные уравнения соболевского типа в квазисоболевых пространствах последовательностей / А.А. Замышляева, Дж.К. Аль-Исави // Вестник ЮУрГУ. Серия: Математическое моделирование и программирование. - 2015. - Т. 8, № 4. C. $113-119$.

Аль Исави Дюавад Кадим Тахир, аспирант, кафедра уравнений математической физики, Южно-Уральский государственный университет (г. Челябинск, Российская Федерачия), jtahir'11@gmail.com.

Поступила в редакцию 7 ноября 2015 г. 